\title{
Perancangan Alat Pembelah Bambu
}

\author{
Wahyudhi Sutrisno'), Rifandi Dwi Styawan²), Benny Wibowo ${ }^{3)}$ \\ Universitas Islam Indonesia
}

\author{
Jalan Kaliurang No.Km. 14,5, Besi, Umbulmartani, Kec. Ngemplak, Kabupaten Sleman, Daerah \\ Istimewa Yogyakarta, Indonesia \\ Email:wahyudhi.sutrisno@uii.ac.id
}

\begin{abstract}
ABSTRAK
Desa Kemiri memiliki berbagai macam mata pencarian, salah satunya merupakan pengrajin anyaman besek. Pengrajin anyaman besek sampai saat ini hanya menggunakan alat tradisional dalam membelah bambu menjadi untaian yang lebih tipis. Hal ini menghabiskan banyak waktu dan tenaga dalam pengerjaannya. Oleh karena itu perlu dilakukan inovasi proses pembelahan bambu dengan cara membuat alat pemecah bambu dengan tujuan agar pembelahan bambu dapat berjalan dengan cepat sehingga produktivitas pengrajin anyaman besek dapat meningkat. Metode pelaksanaannya terdiri dari tiga tahap yang digunakan, tahap pertama yaitu tahap desain alat, tahap kedua yaitu tahap pemilihan bahan dan yang terakhir yaitu tahap pembuatan alat. Berdasarkan hasil simulasi alat pembelah bambu ini maka diperoleh hasil yaitu alat ini dapat memecah bambu menjadi 8 bagian bambu tipis.
\end{abstract}

Kata Kunci: Desa Kemiri, Besek, Pengrajin, Bambu, Inovasi

\section{ABSTRACT}

Kemiri Village has various kinds of livelihoods, one of which is a craftsman of besek weaving. Until now, besek craftsmen have only used traditional tools to split bambu into thinner strands. This takes a lot of time and effort in the process. Therefore it is necessary to innovate the bamboo splitting process by making a bambu splitting device for the bamboo splitting to run quickly so that the productivity of the besek woven craftsman can increase. The method of implementation consists of three stages used, the first stage is the design stage of the tool, the second stage is the stage of selecting materials and the last stage is the stage of making tools. Based on the simulation results of this bamboo splitter, the result is that this tool can split bambu into 8 thin bamboo sections

Keyword: Kemiri Village, Besek, Craftsmen, Bamboo, Innovate

\section{Pendahuluan}

Desa Kemiri merupakan salah satu desa yang terletak di Kabupaten Purworejo, Provinsi Jawa Tengah. Desa ini berada di perbatasan Kabupaten Purworejo dan Wonosobo. Selain sebagai petani, sebagian masyarakat Desa kemiri mempunyai mata pencarian sebagai pengrajin anyaman besek. Pengrajin anyaman besek merupakan mata pencarian yang biasanya diwariskan secara turun menurun. Bambu merupakan bahan baku utama untuk membuat besek. Pembuatan besek memerlukan rangkaian proses yang panjang. Proses pembuatan besek dimulai dari membelah bambu. Masyarakat pengrajin Desa Kemiri masih menggunakan alat sederhana dalam melakukan pembelahan bambu yaitu dengan menggunakan sabit atau golok. Penggunaan golok untuk membelah bambu jelas memerlukan waktu yang lama, karena mereka hanya dapat membelah bambu dengan satu golok pada satu waktu. Selain itu juga ukuran bambu yang dihasilkan berbeda satu sama lainnya, sehingga memerlukan waktu dan tenaga tambahan lagi untuk menyempurnakannya. Dari sisi keselamatan kerja, proses pembelahan bambu dengan hanya menggunakan golok secara manual, sangat berpotensi menimbulkan terjadinya kecelakaan kerja. Golok yang digunakan bisa melukai 
tangan pengrajin dana tau tangan terluka oleh bilah bambu yang sedang diirat. Hal ini berarti pembelahan bambu secara tradisional tidak efisien berkaitan dengan waktu dan tenaga serta mempunyai potensi kecelakaan kerja. Berdasarkan latar belakang permasalahan tersebut, maka dibutuhkan inovasi pembelahan bambu dengan cara merancang alat pembelah bambu yang dapat mempercepat proses pembelahan bambu sekaligus menghemat tenaga pengrajin besek tersebut, sehingga diharapkan dapat meningkatkan produktivitas pengrajin besek. Alat pembelah bambu tersebut juga harus aman digunakan oleh pengrajin.

\section{Tinjauan Pustaka}

Menurut Dransfield dan Widjaja (1995), bambu merupakan tumbuhan yang batangnya berbentuk bulat, mempunyai ruas, berbuku-buku, berongga, serta mempunyai cabang, berimpang, dan juga alur batang yang menonjol. Bambu termasuk salah satu hasil hutan yang banyak dimanfaatkan oleh masyarakat baik di pedesaan maupun perkotaan (Widjaja dan Karsono, 2004). Bambu dapat dimanfaatkan sebagai bahan baku obat-obatan (Sujarwo, Arinasa dan Peneng, 2010). Bambu digunakan dalam konstruksi untuk dinding dan partisi (Ediningtyas dan Winarto, 2012). Selain itu, Bambu ditangan pengrajin, bisa diolah menjadi perabotan rumah tangga (Mayasari dan Suryawan, 2012).

Salah satu hasil kerajinan yang terbuat dari Bambu adalah Besek. Besek merupakan tempat yang terbuat dari anyaman bambu bertutup bentuknya segi empat (Poerwadarminta, 1995) Besek termasuk kemasan tradisional yang sudah lama menjadi ciri khas bangsa Indonesia. Besek biasanya digunakan sebagai alat untuk menyimpan bumbu-bumbu dapur seperti cabai, kunyit, lengkuas, bawang merah dan bawang putih dan bumbu dapur lainnya. selain itu besek dimanfaatkan sebagai wadah nasi dan lauk atau bingkisan sembako untuk keperluan kenduri. Sekarang besek juga digunakan sebagai bungkus penyimpan makanan seperti bungkus gudeg.

Salah satu kendala yang biasa dihadapi oleh para pengrajin anyaman besek terutama berhubungan dengan proses pemotongan bambu. Hal ini karena pemotongan bambu masih dilakukan secara tradisional atau menggunakan alat sederhana berupa golok atau sabit. Proses ini memerlukan waktu yang lama, dengan tenaga yang besar dan juga potensi kecelakaan kerja. Oleh karena itu perlu dilakukan inovasi agar kendala tersebut dapat diatasi. Menurut Everett (1983), inovasi merupakan ide, konsep ataupun gagasan yang didasari dan diterima oleh seseorang dan atau suatu kelompok sebagai hal baru untuk diterapkan. Sedangkan Edquist (2001) menyatakan bahwa inovasi merupakan ciptaan baru yang memiliki nilai ekonomi yang berarti signifikan yang umumnya dilakukan oleh perusahaan atau terkadang oleh para individu. Inovasi alat pembelah bambu diharapkan dapat meningkatkan produktivitas pengrajin anyaman besek.

\section{Metodologi Penelitian}

1) Observasi ke pengrajin anyaman besek Desa Kemiri

Melakukan observasi secara langsung ke pengrajin-pengrajin anyaman becek Desa Kemiri yang berjumlah 19 pengrajin. Observasi dilakukan dengan cara mengamati proses pembuatan besek disertai dengan mewawancarai pengrajin anyaman becek untuk mendapatkan informasi mengenai urutan proses produksi dan juga kendala-kendala yang dihadapi pengrajin anyaman besek tersebut. Dari observasi yang dilakukan, maka dapat diketahui bahwa proses pembelahan bambu masih dilakukan dengan menggunakan alat tradisional yaitu dengan menggunakan golok. Proses pembelahan bambu ini termasuk proses yang sulit dan memakan waktu yang lama serta juga menghabiskan banyak tenaga pengrajinnya. Berdasarkan hasil wawancara, diketahui bahwa pengrajin anyaman bambu Desa Kemiri berharap ada alat yang bisa membantu mereka dalam membelah bambu dengan lebih efisien. 
2) Pembuatan desain alat pemecah bambu

Berdasarkan hasil observasi ke pengrajin anyaman besek Desa Kemiri, maka diperoleh informasi mengenai alat pemecah bambu yang sesuai dengan kebutuhan pengrajin. Informasi ini kemudian dilengkapi dengan melakukan studi literatur untuk mengetahui alat-alat pemotong bambu yang sudah ada. Dari hasil observasi dan studi literatur, kemudian didesain alat pemecah bambu dengan menggunakan Software Autodesk Inventor Professional 2017. Software Autodesk Inventor Professional dipilih karena memiliki keunggulan yaitu mempunyai kemampuan Parametic Solid Modeling dimana pendesain dapat merevisi atau memodifikasi desain yang sudah ada tanpa harus mendesain ulang sebagian atau seluruhnya (https://taufiqdrafting13.blogspot.com/2017/07/mengenal-kelebihan-autodesk-inventor.html).

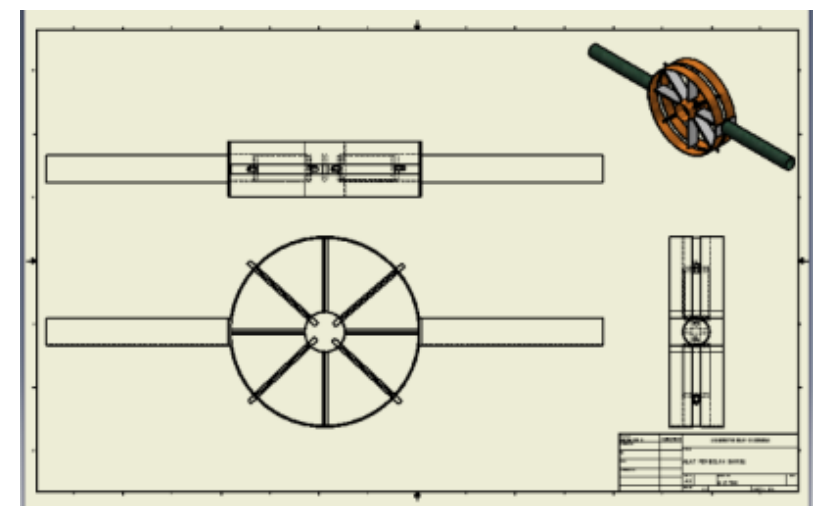

Gambar 1. Desain Alat Pembelah Bambu

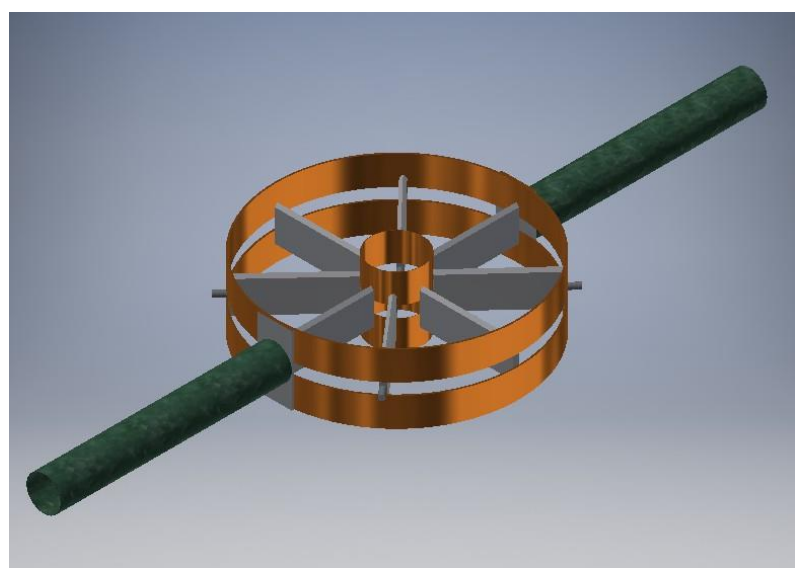

Gambar 2. Prototipe Tiga Dimensi Alat Pemecah Bambu

3) Pemilihan bahan alat pemecah bambu

Setelah alat pemecah bambu selesai didesain, maka tahap berikutnya adalah memilih bahanbahan yang akan digunakan untuk membuat alat pemecah bambu tersebut. Pemilihan bahan ini bertujuan agar alat yang dihasilkan bisa digunakan dalam waktu yang lama serta memiliki ketahanan yang baik. Bahan-bahan utama yang digunakan adalah pelat besi yang digunakan sebagai rangka dan mata pisau, serta Besi Hollow yang digunakan sebagai handel dan pipa tengah. 


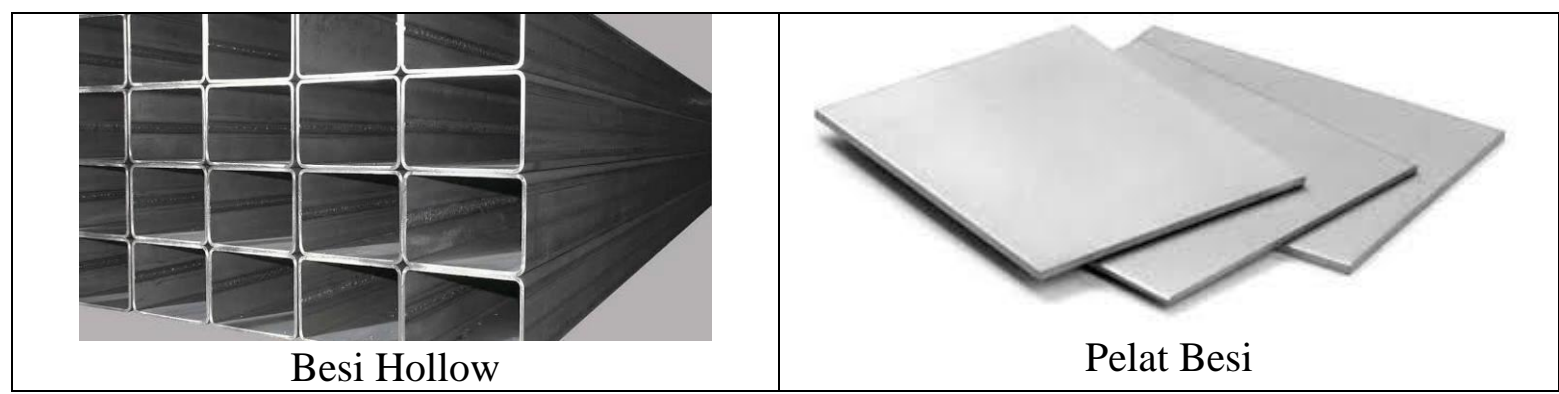

Gambar 3. Bahan Utama Alat Pemecah Bambu

4) Pembuatan Alat Pemecah Bambu

Tahap terakhir ini yaitu pembuatan alat pemecah bambu setelah pembuatan desain dan pemilihan bahan telah selesai. Proses pembuatan alat ini dilakukan dengan melakukan pengelasan menggunakan las karbit (Welding dan Cutting Oxy-Fuel). Welding dan Cutting Oxy-Fuel merupakan pengelasan secara manual dimana permukaan yang akan disambung mengalami pemanasan sampai cair oleh nyala gas acetylene dan oksigen (https://safetyheatlh.wordpress.com/2016/08/26/safety-welding-dan-cutting-oxy-fuel).

Pembuatan mata pisau berasal dari plat besi yang diasah sehingga menjadi tajam dengan menggunakan mesin gerinda. Setelah bahan-bahan sudah di rakit, maka kemudian dilakukan finishing agar alat pembelah bambu terlihat lebih rapi dan bagus.

Tabel 1. Bahan-bahan Alat Pemecah Bambu

\begin{tabular}{lc}
\hline \multicolumn{1}{c}{ Bahan-bahan } & Jumlah \\
\hline Mur, baut, dan ring & 8 \\
Plat besi (Rangka) & 1 \\
Plat besi (8 mata pisau) & 8 \\
Handle (besi pipa Hollow) & 2 \\
Pipa tengah (bisa pipa hollow) & 1 \\
\hline
\end{tabular}

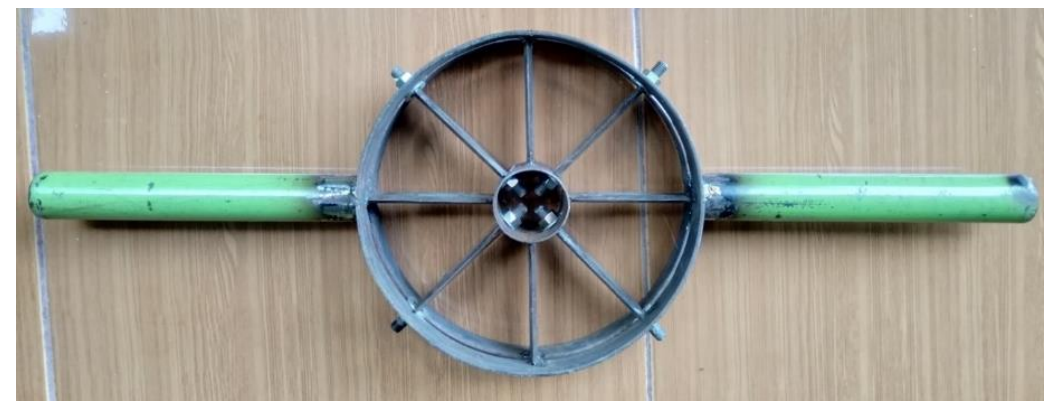

Gambar 4. Tampak atas Prototipe Alat Pemecah Bambu

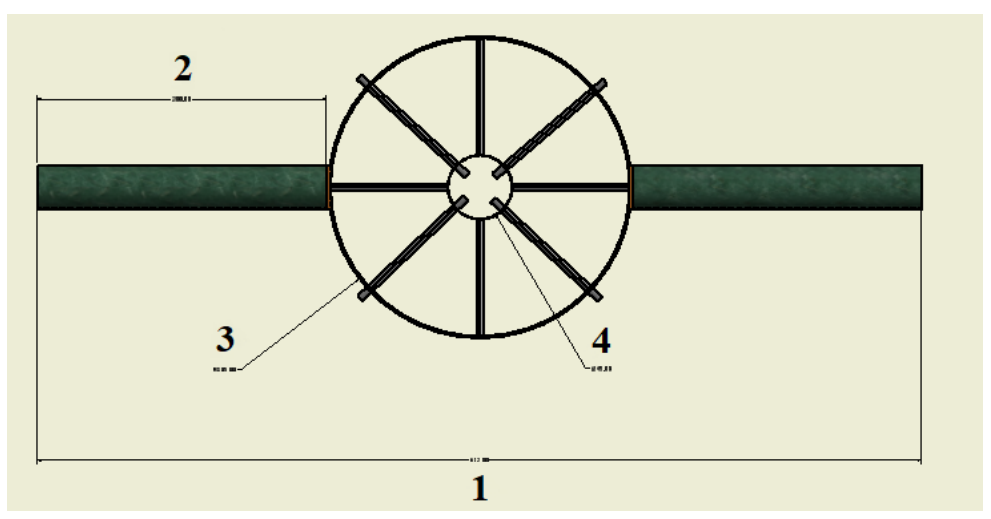


Gambar 5. Dimensi Alat Pembelah Bambu

Keterangan gambar dimensi alat pembelah bambu:
1) Panjang total
: $610 \mathrm{~mm}$
2) Panjang handle
: $200 \mathrm{~mm}$
3) Diameter ring luar
: $210 \mathrm{~mm}$
4) Diameter ring dalam
: $45 \mathrm{~mm}$

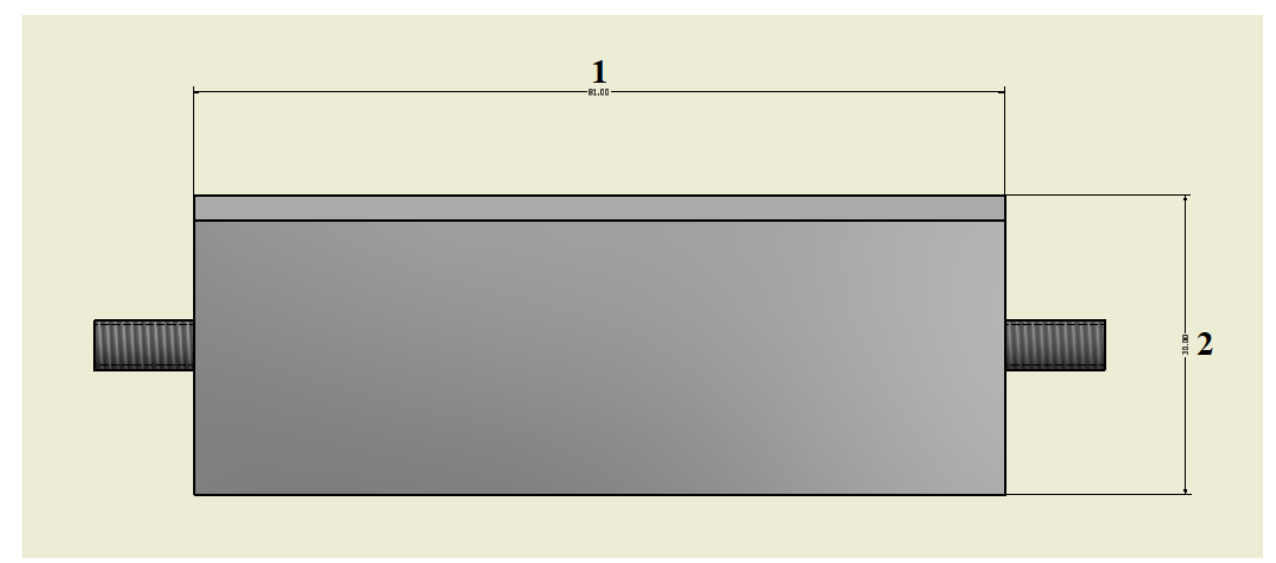

Gambar 6. Dimensi Pisau Alat Pembelah Bambu

Keterangan dimensi :

1) Panjang pisau : $81 \mathrm{~mm}$

2) Lebar pisau : $: 30 \mathrm{~mm}$

5) Sosialisasi alat pemecah bambu

Pada tahap ini dilakukan sosialisasi serta simulasi alat pembelah bambu pada masyarakat dan pengerajin anyaman besek Desa Kemiri. Selain itu, sosialisasi ini juga bertujuan untuk meminta tanggapan mengenai alat pembelah bambu pada pengerajin anyaman besek dari bambu.

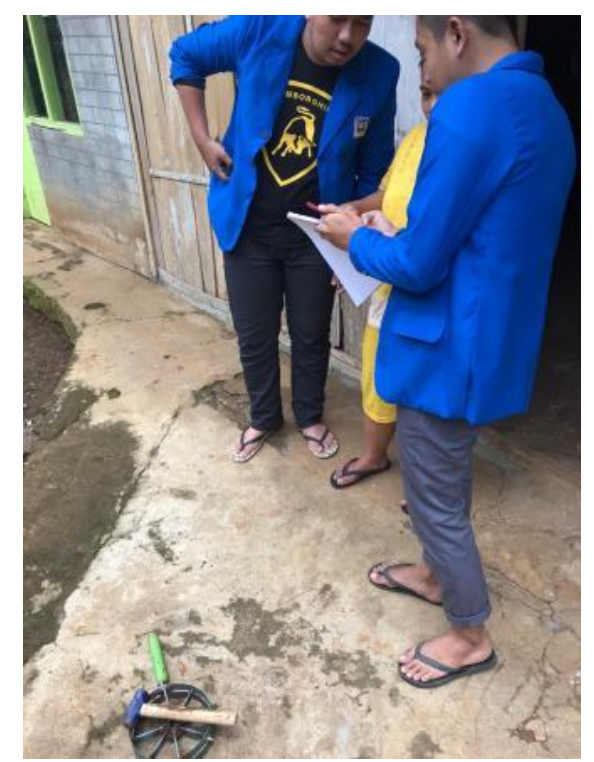

Gambar 5. Simulasi Alat Pembelah Bambu 


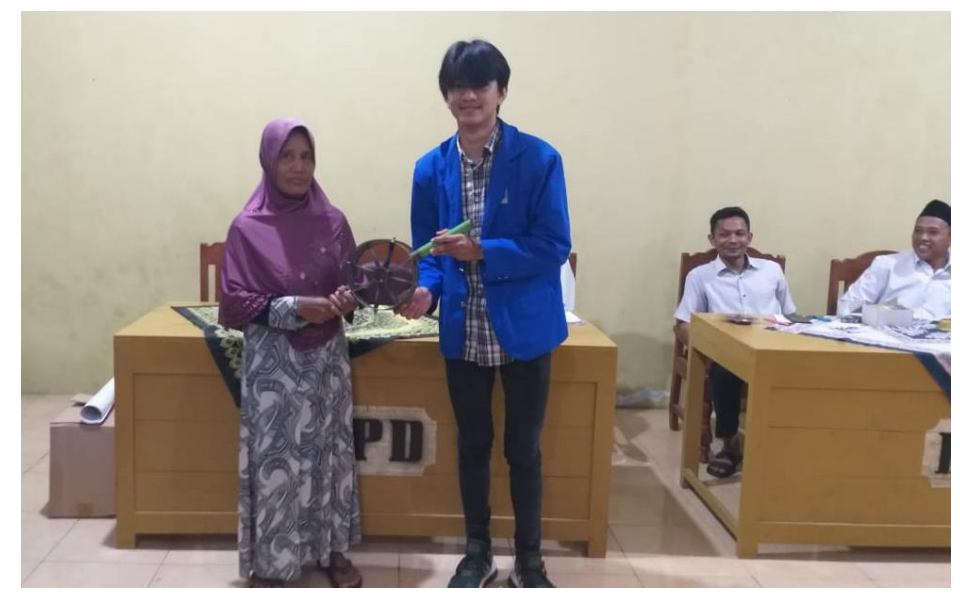

Gambar 6. Sosialisasi Alat Pembelah Bambu

\section{Hasil dan Pembahasan}

Perancangan alat pemecah bambu ini baru sampai pada tahap simulasi penggunaan kepada masyarakat Desa Kemiri khususnya pengrajin anyaman besek. Berdasarkan simulasi penggunaan alat pemecah bambu ini, didapatkan hasil yaitu alat pemecah bambu ini dapat memecah bambu menjadi delapan bagian bambu tipis sekaligus pada satu kali pemakaian pembelahan. Hal ini jelas sangat menghemat waktu dibandingkan bila menggunakan alat tradisional sebelumnya. Selain itu juga, tenaga yang dikeluarin oleh pengrajin anyaman besek juga lebih sedikit dibandingkan dengan sebelumnya. Mereka tidak perlu lagi memotong bambu berulang-ulang kali, dimana hal ini jelas menghabiskan banyak tenaga. Keunggulan lain dari penggunaan alat pemecah bambu ini adalah, menghasilkan ukuran bambu yang sama lebarnya, berarti mengurangi tingkat kesalahan jika dibandingkan dengan menggunakan alat tradisional yang sebelumnya. Alat pemecah bambu ini juga mudah digunakan oleh siapa saja, hal ini dibuktikan ketika simulasi berlangsung, kaum wanita juga dapat menggunakan alat ini dengan baik. Alat pemecah bambu ini juga lebih aman daripada menggunakan golok karena pengguna terhindar dari resiko terluka terkena sabetan pisau saat membelah bambu. Pengguna cukup memegang gagang yang aman dan nyaman dipegang dengan kedua tangan, dimana gagang ini jauh dari pisau pemotong bambunya

Tabel 2. Perbandingan Sebelum dan Sesudah Pengabdian

\begin{tabular}{lll}
\hline \multicolumn{1}{c}{ Indikator } & \multicolumn{1}{c}{ Golok } & \multicolumn{1}{c}{ Alat Pemecah Bambu } \\
\hline Waktu Pengerjaan & 155 detik & 30 detik \\
Penggunaan Tenaga & Besar & Sedikit \\
Hasil Pemotongan & Ukuran tidak sama besar & Ukuran sama besar \\
Resiko Kecelakaan & Tinggi, luka sabetan golok & Rendah, hampir tidak ada resiko \\
\hline
\end{tabular}

Pada umumnya respon masyarakat pengrajin anyaman besek Desa Kemiri terhadap alat pemecah bambu ini sangat baik. Mereka berharap alat pemecah bambu ini dapat diproduksi secara massal agar dapat mereka gunakan.

\section{Daftar Pustaka}

Dransfield, S. and E. A. Widjaja, (1995). Plant Resources of South-East Asia No. 7. Bambus. Leiden: Prosea Foundation Bogor

Ediningtyas, D., dan Winarto, V. (2012). Mau Tahu Tentang Bambu? Jakarta: Kementrian Kehutanan.

Edquist, C. (2001). : “The Systems of Innovation Approach and Innovation Policy: An Account of the State of the Art". Lead paper presented at the DRUID Conference, Aalborg, June 12-15, 2001, under theme F: 'National Systems of Innovation, Institutions and Public Policies' 
(Invited Paper for DRUID's Nelson-Winter Conference). http://www.druid.dk/conferences/ nw/paper1/ edquist.pdf

Everett M. Rogers. 1983. Diffusion of Innovations. London: The Free Press.

https://taufiqdrafting13.blogspot.com/2017/07/mengenal-kelebihan-autodesk-inventor.html

https://safetyheatlh.wordpress.com/2016/08/26/safety-welding-dan-cutting-oxy-fuel

Mayasari, A., dan Suryawan, A. (2021). Keragaman Jenis Bambu dan Pemanfaatannya di Taman Nasional Alas Purwo. Info BPK Manado, 2(2), 139-154.

Poerwadarminta, W.J.S.. Kamus Umum Bahasa Indonesia. Jakarta: Balai Pustaka.1995.

Sujarwo, W., Arinasa, I. B. K., dan Peneng, I. N. (2010). Inventaris Jenis-Jenis Bambu yang Berpotensi Sebagai Obat di Kabupaten Karangasem Bali. Buletin Kebun Raya, 13(1).

Widjaja, E. A. dan Karsono. (2004). Keanekaragaman bambu di Pulau Sumba. Jurnal Biodiversitas, 6 (2): 95-99. 